\title{
Focused Ion Beam-Scanning Electron Microscope
}

National Cancer Institute

\section{Source}

National Cancer Institute. Focused Ion Beam-Scanning Electron Microscope. NCI

Thesaurus. Code C78815.

An instrument that combines the use of a focused beam of gallium ions to etch or coat a sample with a scanning electron microscope to image the sample. 